\title{
Light Hydrocarbons in the Tropospheric Boundary Layer Over Tropical Africa
}

\author{
J. RudolPh, A. KHEdim, AND B. BonSANG ${ }^{1}$ \\ Institut für Atmosphärische Chemie, Forschungszentrum Jülich, Jülich, Germany
}

\begin{abstract}
Fifty measurements of nonmethane hydrocarbons (NMHC) and several other trace gases were made over an equatorial rain forest in February 1988 as part of the DECAFE experiment. The measurements were made independently by two different laboratories. Each laboratory used its own sample containers, gas chromatographic measurement procedure, and calibration. Also, the altitudinal distribution of the samples differed. Apart from propene and $i$-pentane for which a substantial difference in the absolute calibration existed between the two laboratories, the average results were very similar, and the vertical profiles were identical within the scatter of the data. For NMHC with longer atmospheric residence times (e.g., ethane and acetylene) the average results agreed within a few percent. In the boundary layer, only small gradients could be found. In all cases where a significant vertical gradient existed, there was an increase of the mixing ratios with increasing altitude. This can be explained by the different origin of the air masses at different altitudes. Above the boundary the trace gas mixing ratios decrease. The observed NMHC pattern can primarily be described as photochemically aged emissions from biomass burning. The observed depletion of the photochemically reactive NMHC also agrees with the occurrence of enhanced ozone levels in the boundary layer.
\end{abstract}

\section{INTRODUCTION}

Biomass burning and emissions from vegetation have been identified as important sources for hydrocarbons in tropical regions [cf. Zimmerman et al., 1988; Greenberg and Zimmerman, 1984; Greenberg et al., 1984; Crutzen et al., 1985; Rasmussen and Khalil, 1988; Bonsang et al., 1988]. These emissions have a significant impact on the photochemistry of the atmosphere on a large scale and can contribute substantially to the global budget of tropospheric ozone [cf. Chatfield and Delany, 1990]. However, most of the published studies dealing with field measurements of emissions from biomass burning were made over tropical South America, especially in the Amazon basin. Here we present measurements made by the Centre des Faibles Radioactivités in Gif-sur-Yvette and the Institut für Atmosphärische Chemie in Jülich over an equatorial rain forest in Africa during the savanna burning season. In this paper we will focus on the distributions of nonmethane hydrocarbons (NMHC) in the planetary boundary layer and above the forest canopy.

\section{EXPERIMENT}

About 50 whole air samples for hydrocarbon measurements were collected during the Dynamique et Chimie de l'Atmosphere en Forêt Equatoriale (DECAFE) experiment in February 1988 in and above a tropical rain forest in the People's Republic of the Congo (about $3^{\circ} \mathrm{N}, 15^{\circ} \mathrm{E}$ ). A detailed description of the sampling area, its surroundings, and the meteorological conditions for the 1988 DECAFE campaign is given by Fontan et al. [this issue]. The samples were collected in evacuated stainless steel spheres of $6 \mathrm{dm}^{3}$ (Gif) and $2 \mathrm{dm}^{3}$ (Jülich) volume with metal bellow valves. Inside

\footnotetext{
${ }^{1}$ Centre des Faibles Radioactivités, Laboratoire Mixte CNRS/ CEA, Gif-sur-Yvette, France.

Copyright 1992 by the American Geophysical Union.

Paper number 91JD00289.

0148-0227/92/91JD-00289\$05.00
}

the forest the samples were collected manually. Except for three samples which were collected using a tethered balloon, the samples from above the forest canopy were collected during six flights on February 15, 17, 19, 20, 21, and 23. For sampling, the containers were connected to a permanently flushed stainless steel inlet line. The sampling altitudes for the two laboratories had a different distribution and, in general, no parallel samples were collected.

The samples were analyzed in the laboratories in Gif-surYvette or Jülich by flame ionization detector (FID) gas chromatography. The hydrocarbons were preconcentrated cryogenically and separated on an $\mathrm{Al}_{2} \mathrm{O}_{3} / \mathrm{KCl}$ porous layer open tubular column (Gif) or a combination of a micropacked Porapak QS column with a DB-5 $60 \mathrm{~m}$ fused silica capillary column (Jülich). The reproducibility of the measurements is $5-10 \%$ and the lower limit of detection 5-20 ppt. The estimated accuracy of the calibrations is about $20 \%$. Both laboratories have their own absolute calibrations which have been intercompared for several NMHC as part of larger intercalibration exercises, but no changes or adjustments of the calibrations have been made. Thus the results from the two laboratories are fully independent from each other. More details of the experimental procedures are given by Bonsang et al. [1987, 1988], Bonsang and Lambert [1985], Rudolph [1988], and Rudolph et al. [1986].

Both laboratories measured light alkanes (ethane, propane, $i$ - and $n$-butane, and $i$ - and $n$-pentane), light alkenes (ethene, propene, and 1-butene), and acetylene. In this paper we also report results of benzene and toluene measurements made in Jülich. The Jülich samples were also analyzed for carbon monoxide and carbon dioxide by a gas chromatographic method similar to the one described by Heidt [1978].

\section{Comparison of the Two Data Sets and the Vertical Profiles}

For several NMHC, both laboratories made measurements in air samples distributed from a common tank during a NMHC intercomparison experiment in 1987. The NMHC mixing ratios in these samples were between several $10 \mathrm{ppt}$ 


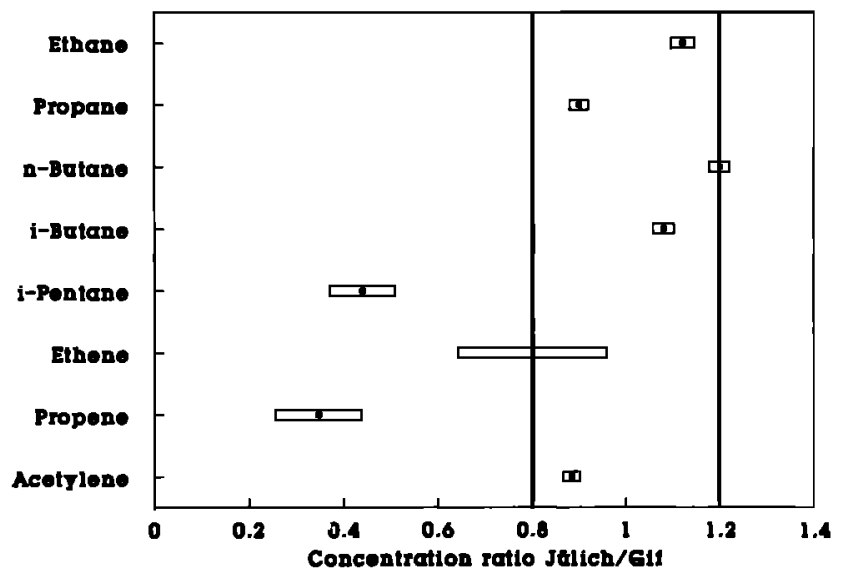

Fig. 1. Comparison of calibrations between Gif-sur-Yvette and Jülich. The data dots show the average ratio of the results from the comparison of six pairs of aliquots from the same air sample and its errors. The solid vertical line indicates the range of uncertainty calculated from the accuracy given by the two laboratories.

and a few parts per billion. In Figure 1 the ratio of the averaged results reported by the two laboratories (measurements in six different pairs of aliquots) is shown. Except for propene and $i$-pentane the NMHC ratios are all within the estimated range of $20 \%$ accuracy for the absolute calibrations. For propene and $i$-pentane the results differ significantly from the ideal value of 1 . Excluding them, the average ratio of the Jülich/Gif calibrations is 1.0 with a standard deviation of $16 \%$ and a relative error of $7 \%$. The average of the Jülich measurements of the propene and $i$-pentane mixing ratios in these samples were 44 and $20 \mathrm{ppt}$, respectively. These quite low mixing ratios are not very suitable for a comparison of calibrations, and there are several possibilities to explain that the Gif propene and $i$-pentane measurements were consistently higher in these samples. Blank values or sample contaminations for the Gif measurements can essentially be ruled out. Effects of a magnitude to explain the observed difference would have been noticed in the instrument tests. Another possibility are interferences from halocarbons. Although these compounds give a relatively weak response in the FID, this may be sufficient to cause a fake hydrocarbon signal of some $10 \mathrm{ppt}$ if they are not separated from the hydrocarbons. In contrast to the Jülich detection system the Gif instrument did not have a combined FID/electron capture (EC) detector system. Therefore such interferences would not have been noticed. In this case the Gif measurements may be too high by several $10 \mathrm{ppt}$. For propene and $i$-pentane mixing ratios of several hundred parts per trillion or more this would have only marginal effects. Another possibility are differences in the propene and $i$-pentane calibrations. In this case there would be a substantial and systematic difference between all propene and $i$-pentane measurements made by Gif and Jülich. In this case the data from one of the laboratories have to be corrected. We have not yet been able to identify the source of the discrepancy in the propene and $i$-pentane intercalibrations. We decided to correct the Gif data by factors of $\mathbf{0 . 3 5}$ and 0.44 , respectively, although the resulting data sets may be too low if the discrepancy is not due to an error in the Gif calibration. We use this correction since it results in an underestimation of the corrected data even if the discrep-

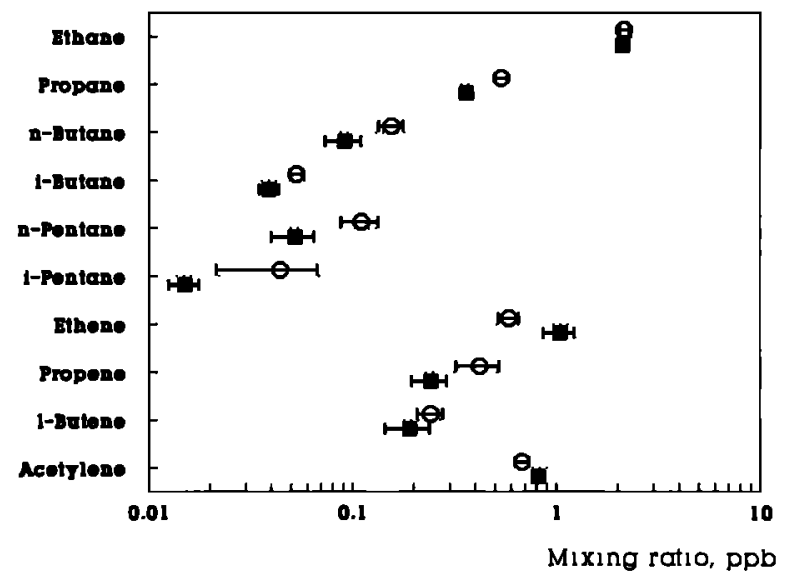

Fig. 2. Comparison of the average mixing ratios from all NMHC measurements made during the DECAFE experiment by the laboratories in Gif-sur-Yvette (open circles) and Jülich (solid squares).

ancy is caused by one of the other mentioned possibilities. Thus the corrected propene and $i$-pentane data provide at least a reasonable lower limit.

In Figure 2 the average values for the Gif and Jülich NMHC measurements are compared. The averages include all altitude levels. In general, the Gif and Jülich averages agree within $30 \%$. The average value for the Jülich/Gif NMHC concentration ratios is 0.82 with a standard deviation of 0.42 and an error of 0.14 . On the average, there is no significant difference between the two data sets; the only exceptions are $i$ - and $n$-pentane. We also have to consider that the distribution of the sampling altitudes for the two data sets differs. About $60 \%$ of the Gif samples were collected below $100 \mathrm{~m}$ but only $25 \%$ of the Jülich samples. For compounds with a systematic vertical gradient this could cause differences between the two averaged mixing ratios.

No systematic changes could be identified between the profiles measured during the different flights, and we therefore combined the results from all flights. In Figure 3 the vertical distributions for some NMHC are shown. Only measurements from above the forest canopy are included. Within the boundary layer, only small or insignificant gradients can be observed, but for most of the NMHC and $\mathrm{CO}$ there seems to be a decrease directly above the boundary layer (about $3 \mathrm{~km}$ ). Inside the boundary layer there are indications of a slight increase of the mixing ratios with increasing altitude. For ethane, acetylene, and $\mathrm{CO}$, linear regressions give positive gradients of $0.19 \pm 0.06,0.031 \pm$ 0.036 , and $24.3 \pm 12 \mathrm{ppb} \mathrm{km}^{-1}$, respectively. This can be explained by the different origin of the air masses at different altitudes. At low altitudes $(925 \mathrm{hPa}$ level) the isentropic backtrajectories indicate airflow from coastal regions and the Atlantic (west to southwest of the sampling area). At higher altitudes $(700 \mathrm{hPa}$ level) the air masses were advected from the savanna regions located northwest of the sampling area. In these regions, substantial biomass burning was observed [Fontan et al., this issue]. The relatively small gradient and the rather small unsystematic variability observed in the profiles of the less reactive, longer lived compounds indicate that vertical exchange within the boundary layer is fast enough to smooth out most of the concentration gradients which must exist between air masses from the savanna areas and coastal regions. For the more reactive NMHC (alkenes, 

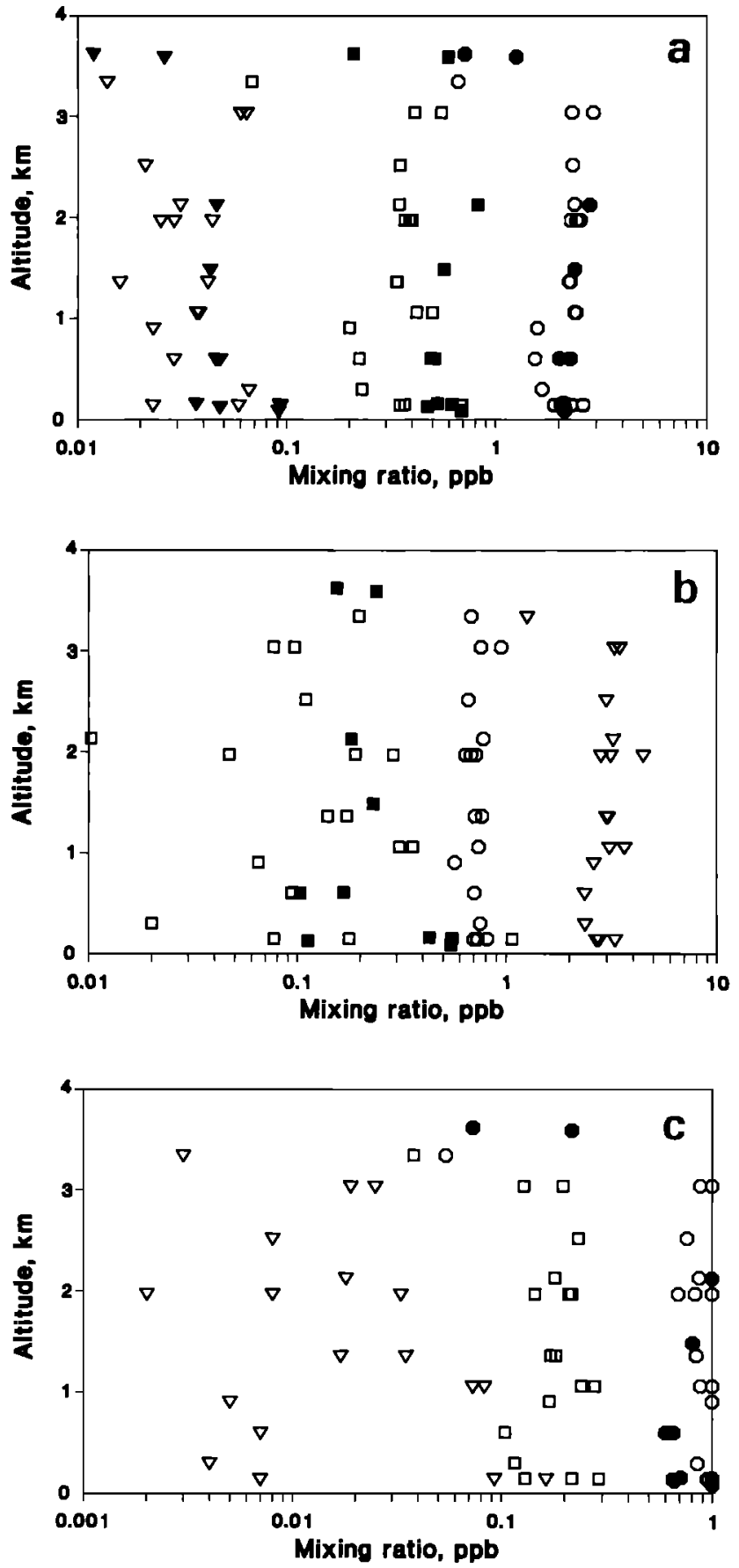

Fig. 3. Vertical profiles of some selected trace gases measured during the DECAFE campaign in 1988. Solid symbols, data from Gif-sur-Yvette; and open symbols, data from Jülich. (a) Ethane (circles), propane (squares), and $i$-butane (triangles). (b) Methylchloride (circles), l-butene (squares), and $\mathrm{CO} / 100$ (triangles). (c) Acetylene (circles), benzene (squares), and toluene (triangles).

alkyl benzenes, heavier alkanes) there is a large unsystematic variability which prevents the identification of any systematic gradient within the boundary layer. For none of these compounds a statistically significant gradient could be observed. However, the uncertainties in their vertical gradients do not rule out relative changes between 10 and $25 \%$ $\mathrm{km}^{-1}$. Within the scatter of the data there is no difference between the Gif and Jülich NMHC profiles.

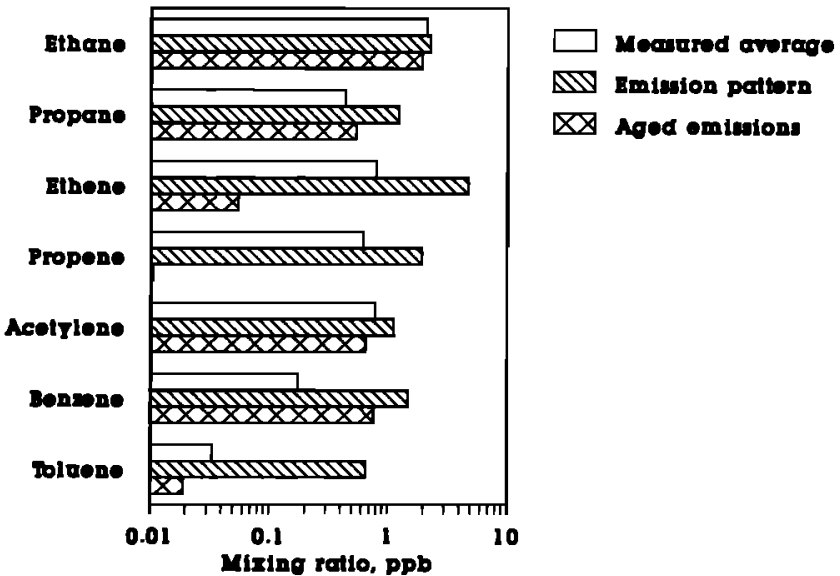

Fig. 4. Comparison between average boundary layer NMHC mixing ratios and the pattern of biomass burning emissions [Crutzen et al., 1985]. To allow a better comparison, the emission pattern is scaled to the CO "excess" (difference between boundary layer and free tropospheric mixing ratios).

\section{THE NMHC PATTERN}

If our assumption is correct, that the observed NMHC concentrations are primarily due to local or regional biomass burning, we can expect that the observed NMHC pattern is similar to the emission pattern of biomass burning. A typical tracer for biomass burning which has a sufficiently long atmospheric lifetime is CO. However, there is a significant atmospheric background concentration of $\mathrm{CO}$ which cannot be directly ascribed to local or regional biomass burning activities. Although the measurements were made near the equator, the backtrajectories indicate northern hemispheric origin of the air masses. Our $\mathrm{CO}$ measurements above the boundary layer range around $150 \mathrm{ppb}$, comparable to the northern hemispheric background. We therefore have to subtract this value from our CO measurements inside the boundary layer before we scale the NMHC emission pattern to $\mathrm{CO}$. In Figure 4 the measured average NMHC mixing ratios are compared with the emission ratios scaled to the CO excess. For NMHC with longer atmospheric lifetimes the emission patterns and the atmospheric mixing ratios agree. In Figure $5 a$ the acetylene mixing ratios are plotted versus the ethane mixing ratios for all measurements in the boundary layer and above the forest canopy. There is a statistically significant linear correlation $(R=0.79)$, and the slope of $0.42 \pm 0.06$ is similar to the emission pattern of biomass burning [Crutzen et al., 1985]. Within the scatter of the data the results from both laboratories follow the same regression line. The $\mathrm{CO}$-ethane regression (Figure $5 b$ ) gives a slope of $116 \pm 17$, again comparable to the emission ratios reported by Crutzen et al. [1985]. The slope of the ethanepropane regression line (not shown) is $0.53 \pm 0.14$, still in reasonable agreement with the emission patterns, but the relative error of $26 \%$ is nearly twice as large as for the CO-ethane and acetylene-ethane correlations (each $\pm 15 \%$ uncertainty). From Figure 4 it is evident that the deviations between emission pattern and measured concentrations are more pronounced for the more reactive NMHC. For the most reactive compounds this difference exceeds a factor of 5. This points toward photochemical degradation during transport from the burning regions to the measuring area. 

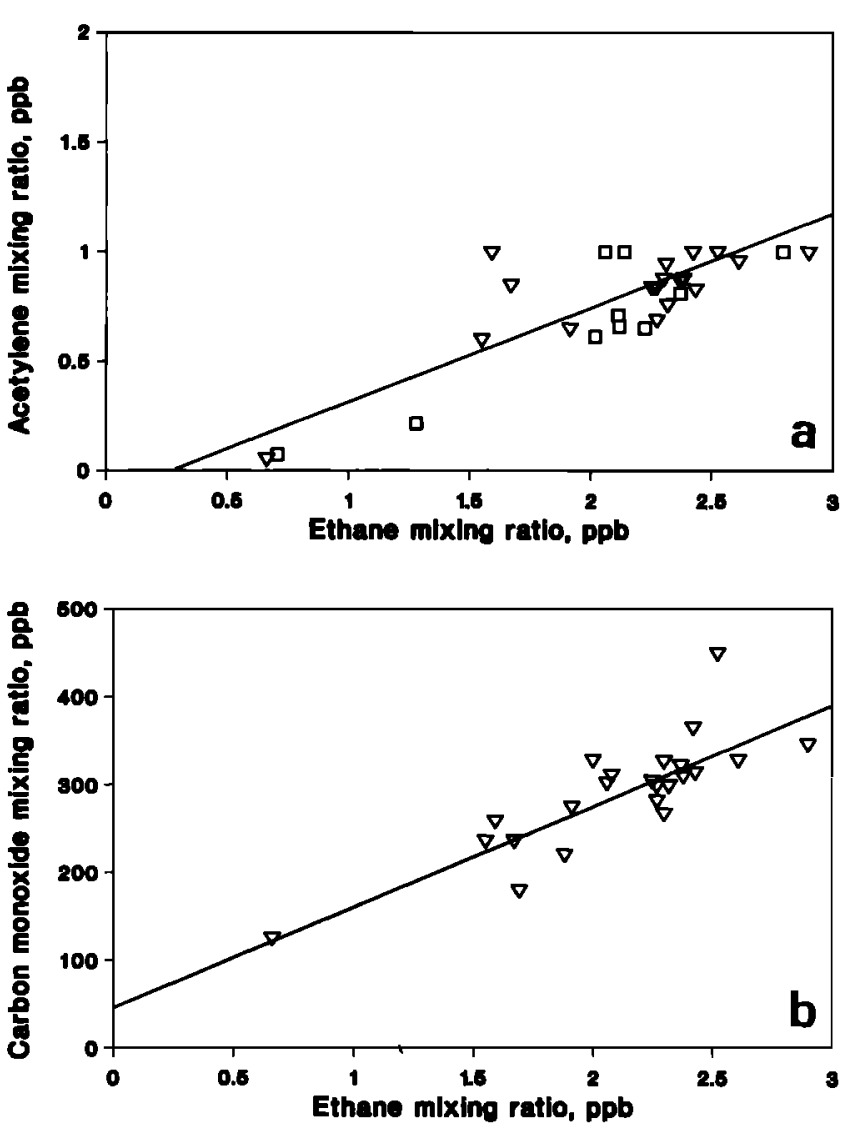

Fig. 5. Examples for the correlations between trace gases measured during DECAFE 1988. (a) Acetylene-ethane: squares, Gifsur-Yvette; triangles, Jülich. (b) Carbon monoxide-ethane: only data from Jülich; no $\mathrm{CO}$ data are available for the Gif-sur-Yvette samples. The solid lines represent a least squares fit to the experimental data.

In order to test this assumption we can compare our measured NMHC mixing ratios with the emission patterns corrected for photochemical removal by $\mathrm{OH}$ radicals. The best agreement for all NMHC except the alkenes is found for a product of time and $\mathrm{OH}$ radical concentration of $5.5 * 10^{11}$ $\mathrm{s} *$ molecules $/ \mathrm{cm}^{3}$. The light alkenes were not included because there are indications of substantial other sources apart from biomass burning (see below). This estimate has a statistical error of about $45 \%$ and corresponds to an average transport time of roughly 2 days and an average $\mathrm{OH}$ radical concentration of $3 * 10^{6}$ molecules $/ \mathrm{cm}^{3}$ [cf. Volz et al., 1981]. Considering the backtrajectories and the probable source regions [Fontan et al., this issue], this time scale seems reasonable. The results of our estimates are included in Figure 4 (cross-hatched bars). For ethane, acetylene, and propane the estimates agree with the measured averages within the error of the measurements. For benzene and toluene the discrepancies are larger but still acceptable if we consider the uncertainties of our estimates. However, the measured ethene and propene values exceed our estimates by more than an order of magnitude and thus do not fit into our simple model. There are several possible explanations for this difference. One possibility is an error in the measurements or calibrations. However, the ethene measurements of Gif and Jülich agree within about $\pm 20 \%$, and this essentially rules out experimental errors as possible explanation. For propene the agreement of the two measurement series is less convincing, but the discrepancy between the two calibrations can hardly account for a difference of nearly 2 orders of magnitude. Moreover, the propene value in Figure 4 is based on the lower of the two calibrations. There are also uncertainties in the emission ratios due to different types of burnt biomass. However, the NMHC emission patterns given by Greenberg et al. [1984] for different types of biomass burning in the tropics (Cerrado and Selva fires) differ, in general, by some $10 \%$, in some cases up to a factor of 2. Again, this is by far not sufficient to explain the observed differences. Another substantial uncertainty is caused by the assumption of a single average transport time for the sampled air masses. More realistically, this average is composed of a variety of different transport times. Since photochemical removal of NMHC results in an exponential decrease with time we obtain an exponentially weighted average. Since the various NMHC have different atmospheric lifetimes, this can result in an overestimate of the removal of the most reactive compounds. We do not know the transport time distribution and therefore we cannot directly estimate the possible effect of this uncertainty. But there is another possibility to put some constraints on this uncertainty. The biomass burning emission ratios for ethene/ toluene are about 7 and for propene/toluene about 3 [Greenberg et al., 1984]. Since toluene reacts slower with $\mathrm{OH}$ radicals than ethene and propene, these ratios represent the upper limit for recent biomass burning emissions. Thus we would expect enhanced toluene levels of about 100 and 200 ppt, respectively, if we try to explain the average excess of roughly $700 \mathrm{ppt}$ ethene or $600 \mathrm{ppt}$ propene by unaged biomass burning emissions. The observed average level of toluene is only $34 \mathrm{ppt}$ of which about $20 \mathrm{ppt}$ are expected from the aged biomass burning plume. Unless we are willing to accept that all the possible uncertainties add up their upper limits into one direction, we have to conclude that there is a contribution from other sources of light alkenes.

There is another possibility to test whether there are alkene sources other than biomass burning. We can use carbon dioxide as an independent tracer for biomass burning. If there are sources of alkenes which do not emit carbon dioxide, we can expect that part of the ethene concentrations found are not correlated with carbon dioxide but with other alkenes. Indeed, a multiple regression analysis showed that the observed ethene mixing ratios can be described as a linear function of the 1-butene and the carbon dioxide concentrations (Figure 6). This correlation is highly significant with a correlation coefficient of 0.969 whereas none of the single component regressions gave a linear dependence of comparable significance. The term describing the ethenebutene correlation differs significantly from zero and thus shows that ethene can only partly be correlated with carbon dioxide. If we accept carbon dioxide as a tracer of the biomass burning sources, we have to consider a possible impact of ethene sources which are not related to biomass burning.

We can test whether the ethene sources which are not correlated with carbon dioxide can explain the difference between the measured ethene mixing ratios and our estimate for aged biomass burning emissions (Figure 4). Both propene and 1-butene are very reactive and their atmospheric residence times in tropical areas are only a few hours. Thus we can only expect a marginal contribution to their atmospheric mixing ratios from an aged biomass burning plume (see also 


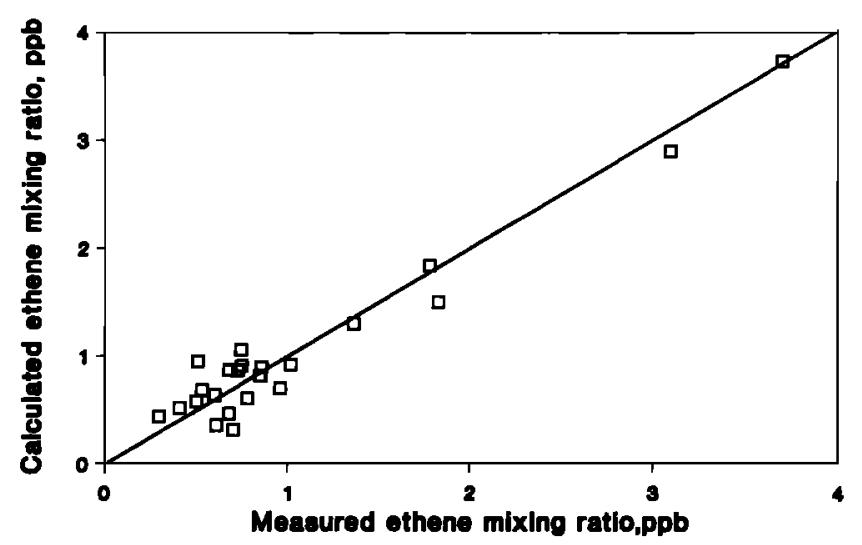

Fig. 6. Comparison of measured ethene mixing ratios with those calculated from a 2-factor linear regression with $l$-butene and carbon dioxide. $\left[\mathrm{C}_{2} \mathrm{H}_{4}\right]=\left[\mathrm{C}_{4} \mathrm{H}_{8}\right] * 3.16+\left[\mathrm{CO}_{2}\right] * 3.14 * 10^{6}-0.9 * 10^{-9}$. The solid line represents a 1:1 correlation.

Figure 4). The average 1-butene mixing ratio is roughly 200 ppt (Figure 2), and the slope of the 1-butene correlated contribution to the ethene mixing ratios is 3.16 . From this we can estimate for the "nonbiomass burning" alkene sources an average contribution of about $650 \mathrm{ppt}$ ethene. This agrees with the observed difference between the measured average ethene mixing ratios and the estimated contribution from aged biomass burning emissions which were scaled to the excess $\mathrm{CO}$ (Figure 4). Microbial production in soils or vegetation emissions are potential sources for alkenes [ $E h$ halt and Rudolph, 1984]. However, our data do not allow any conclusions about the nature of this alkene source.

\section{Comparison With Other NMHC Measurements in Tropical Regions}

The only published NMHC measurements made in Africa during the dry season which are known to us are those from Greenberg et al. [1985]. They report results from 13 samples collected at ground level in Kenya during July and August 1983. These NMHC mixing ratios showed a large variability, even for the less reactive NMHC (ethane, propane, acetylene) and $\mathrm{CO}$. In general, these results were lower than our data from the Congo, but for some samples they report mixing ratios of comparable magnitude. For comparison the average mixing ratios of some selected NMHC are shown in Figure 7a. Also included are the averages from two studies made in Brazil during the dry season in 1980 and 1985 [Greenberg and Zimmerman, 1984; Zimmerman et al., 1988]. On the average our NMHC and CO concentrations are comparable to those observed in Brazil in 1980 and exceed most of the data reported for Kenya in 1983 and Brazil in 1985.

There are also some series of NMHC measurements in tropical regions during the wet season (Bonsang et al. [1987] and data presented by Zimmerman et al. [1988]). Average values for $\mathrm{CO}$ and some of the most abundant NMHC are given in Figure $7 b$. In general, the concentrations during the wet season are lower which supports the importance of biomass burning as a NMHC source in the tropics. But significant NMHC levels still are found during the wet season which again points toward the existence of substantial nonbiomass burning NMHC sources in tropical regions.
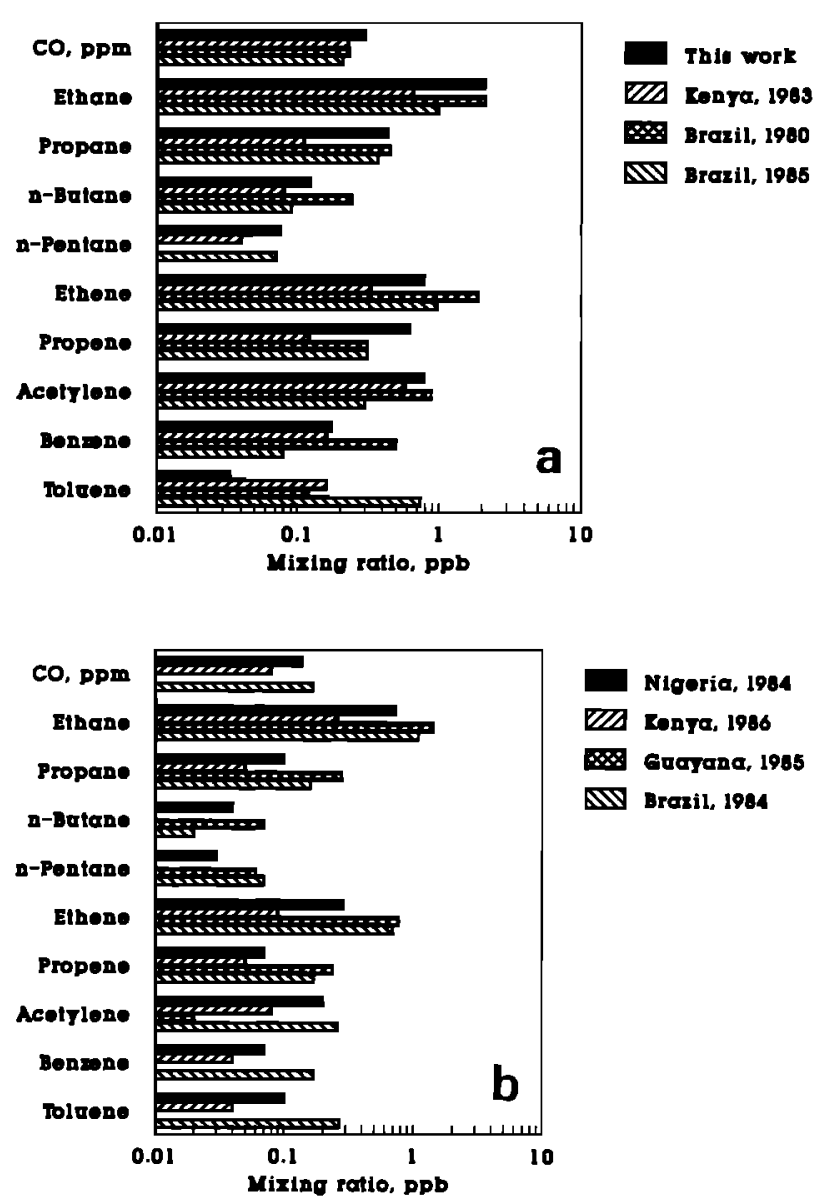

Fig. 7. Comparison of average NMHC mixing ratios measured over tropical Africa and South America. (a) Measurements made during the dry season. (b) Measurements made during the wet season. The data are from Greenberg and Zimmerman [1984] (Brazil, 1980), Greenberg et al. [1985] (Kenya, 1983), Bonsang et al. [1987] (Guyana, 1985), and Zimmerman et al. [1988] (Nigeria, 1984; Brazil, 1984 and 1985; and Kenya, 1986).

\section{ConClusions}

The concentration levels of NMHC in the tropospheric boundary layer over tropical Africa are considerably enhanced during the biomass burning season compared to the wet season. The measurements made during this study over the Congo-Brazzaville showed $\mathrm{CO}$ and $\mathrm{NMHC}$ mixing ratios which exceed those from other studies in Africa. The observed levels are comparable to published data from Amazonia, often even higher. The observed NMHC pattern is primarily characteristic for an aged biomass burning plume. This agrees with the simultaneous observation of strongly enhanced ozone concentrations in the boundary layer [Andreae et al., this issue]. The most likely source regions are the savanna regions northwest of the measuring area. However, the measurements also give indirect but nevertheless strong evidence for the existence of other substantial NMHC sources in tropical Africa. The measurements were made during a period of about 2 weeks, and the airplane flights covered an area of several hundred square kilometers and altitudes up to $3.5 \mathrm{~km}$. Since the less reactive NMHC showed little variability in the boundary layer, it is justified to assume that the results are reasonably representative for this region and season. This is supported by the fact that two 
different measurement series made by different laboratories which followed a different sampling patterh gave very similar results.

Surprisingly enough and in spite of the completely different backtrajectories for the air masses at ground level and at the top of the boundary layer the vertical gradients within the boundary layer were very weak. For the longer lived trace gases $\mathrm{CO}$, acetylene, and ethane there is a small but significant increase with increasing altitude. For the more reactive NMHC a substantial variability can be seen which indicates a somewhat layered structure, but no systematic vertical gradients can be found. Thus the time scales for vertical mixing must be short compared to the average transport times from the source region but not fast enough to smooth out variations of reactive NMHC such as alkenes, heavier alkanes, or aromatic compounds.

Acknowledgment. This work was supported financially by the Bundesminister für Forschung und Technologie of Germany under grant 07441025. The authors thank all participants in the DECAFE experiment for their valuable cooperation and assistance.

\section{REFERENCES}

Andreae, M. O., A. Chapuis, B. Cros, J. Fontan, G. Helas, C. Justice, Y. J. Kaufman, A. Minga, and D. Nganga, Ozone and Aitken nuclei over equatorial Africa: Airborne observations during DECAFE 88, J. Geophys. Res., this issue.

Bonsang, B., and G. Lambert, Nonmethane hydrocarbons in an oceanic atmosphere, J. Atmos. Chem., 2, 257-271, 1985.

Bonsang, B., M. Kanakidou, and G. Lambert, Nonmethane hydrocarbons chemistry in the atmosphere of an equatorial forest: A case of indirect photochemical production of $\mathrm{OH}$ radicals, Geophys. Res. Lett., 14, 1250-1253, 1987.

Bonsang, B., M. Kanakidou, G. Lambert, and P. Monfray, The marine source of $\mathrm{C}_{2}-\mathrm{C}_{6}$ aliphatic hydrocarbons, J. Atmos. Chem., 6, 3-20, 1988

Chatfield, R. B., and A. C. Delany, Convection links biomass burning to increased tropical ozone; however, models will tend to overpredict $\mathrm{O}_{3}, J$. Geophys. Res., 95, 18,473-18,488, 1990.

Crutzen, P. J., A. C. Delany, J. Greenberg, P. Haagenson, L. Heidt, R. Lueb, W. Pollock, W. Seiler, A. F. Wartburg, and P. Zimmer- man, Tropospheric chemical composition measurements in Brazil during the dry season, J. Atmos. Chem., 2, 233-256, 1985.

Ehhalt, D. H., and J. Rudolph, On the importance of light hydrocarbons in multiphase atmospheric systems, Ber. Kernforschung sanlage Jülich. Rep. JÜL-1942, pp. 1-43. Inst. für Atmos. Chemie, Jülich, Germany, 1984

Fontan, J., A. Druilhet, B. Benech, R. Lyra, and B. Cros, The DECAFE program and the Impfondo experiment of February 88 , overview and meteorology, J. Geophys. Res., this issue.

Greenberg, J. P., and P. R. Zimmerman, Nonmethane hydrocarbons in remote tropical, continental, and marine atmospheres, J. Geophys. Res., 89, 4767-4778, 1984.

Greenberg, J. P., P. R. Zimmerman, L. Heidt, and W. Pollock Hydrocarbon and carbon monoxide emissions from biomass burning in Brazil, J. Geophys. Res., 89, 1350-1354, 1984.

Greenberg, J. P., P. R. Zimmerman, and R. B. Chatfield, Hydrocarbon and carbon monoxide in Africa savannah air, Geophys. Res. Lett., 12, 113-116, 1985.

Heidt, L., Whole air collection and analysis, Atmos. Technol., 9, 3-7, 1978.

Rasmussen, P. R., and M. A. Khalil, Isoprene over the Amazon basin, J. Geophys. Res., 93, 1417-1421, 1988.

Rudolph, J., Two-dimensional distributions of light hydrocarbons: Results from the STRATOZ 3 experiment, J. Geophys. Res., 93, 8367-8377, 1988.

Rudolph, J., F. J. Johnen, and A. Khedim, Problems connected with the analysis of hydrocarbons and halocarbons in the non-urban atmosphere, Int. J. Environ. Anal. Chem., 27, 97-122, 1986.

Volz, A., D. H. Ehhalt, and R. G. Derwent, Seasonal and latitudinal variation of ${ }^{14} \mathrm{CO}$ and the tropospheric concentration of $\mathrm{OH}$ radicals, J. Geophys. Res., 86, 5163-5171, 1981.

Zimmerman, P. R., J. P. Greenberg, and C. E. Westberg, Meàsurements of atmospheric hydrocarbons and biogenic emission fluxes in the Amazon boundary layer, J. Geophys. Res., 93, 1407-1416, 1988.

B. Bonsang, Centre des Faibles Radioactivités, Laboratoire Mixte CNRS/CEA, Avenue de la Terasse, F-91198 Gif-sur-Yvette, France.

A. Khedim and J. Rudolph, Institut für Atmosphärische Chemie, Forschungszentrum Jülich, Postfach 1913, D-5170 Jülich, Germany.

(Received July 31, 1990;

revised January 18, 1991; accepted January 23, 1991.) 